\title{
SEASONAL ANALISIS OF TOTAL PREMIUMS WRITTEN OF THE MOTOR THIRD PARTY LIABILITY INSURANCE IN THE CZECH REPUBLIC IN YEARS 2000 - 2016 FROM THE MARKETING PERSPECTIVE
}

The insurance sector is in many ways unique, because insurance companies must use specific marketing tools to satisfy their customers and insurance companies have with customer's long-term relationships. Insurance companies must continuously monitor the insurance market, especially type of demand for insurance products and customer requirements. The number of registered vehicles in the Czech Republic is annually increasing, which causes an increase of total premiums written of the motor third party liability insurance and insurance companies must monitor this insurance product and analyse demand for it. The aim of this article is to analyse the seasonality of total premiums written of motor third party liability insurance in the Czech Republic in years 2000 - 2016.

Keywords: non-life insurance, motor third party liability insurance, seasonal analysis of time series, Henderson moving average filter

\section{Introduction}

The insurance sector is a set of specialized financial activities, otherwise insurance sector has many specifics, for example selling invisible products, high degree of trust between the insurance company and the customer, active approach to the customer and customer relationship management, consulting services for customers and insurance intermediaries have an important role in the insurance sector $[1,2]$.

The insurance market is influenced by many factors that can be divided into external and internal factors. External factors consist of development and volume of gross domestic product, inflation rate, unemployment rate, demography of the population, average wage, volume of expenditures of households, enterprises and institutions. Internal factors consist of demand for insurance products (the size and type of demand and its variability over time), activities of insurance companies and reinsurance undertakings, regulation of the insurance market, activities of the Czech Insurance Association, mediatory activities of insurance intermediaries etc. [3, 4].

There is a number of studies that emphasize the need to analyse and monitor the demand for insurance products and its variability over time with respect to use of the marketing tools and campaigns [5, 6]. Many businesses find that their working capital is fluctuating over time due to fluctuations in demand and seasonality of demand [7]. Some authors stated that seasonality of demand dictates business and marketing strategy in highly seasonal services such as accounting, tourism, advertising, construction, amusement parks, beauty salons, restaurants, car rentals, cinemas, communications, construction materials, education, public utilities, employment agencies, logistics services and financial services [8 - 11].

Insurance services can be divided from the marketing perspective into life insurance and non-life insurance, where the motor third party liability insurance belongs to the nonlife insurance [12]. Nowadays insurance companies use some modern digital marketing tools for getting potential customers (blogging, social media and direct e-mail marketing) [1, 3]. Price is frequently the most important attribute for customers, but in insurance customers buying process are also relevant insurer, bundling strategy and intermediary's recommendation [13].

The motor third party liability insurance is one of the most important lines of insurance business in developed and in developing countries and motor third party liability insurance is a best - selling insurance product in developing countries [14].The number of the road vehicles registered in the Czech Republic is annually increasing and total written premiums of the motor third party liability insurance absolutely increased in years 2000 - 2016 [15].

\footnotetext{
* Monika Eisenhammerova, Jan Chocholac

Department of Transport Management, Marketing and Logistics, Faculty of Transport Engineering; University of Pardubice, Czech Republic

E-mail: jan.chocholac@upce.cz
} 


\section{Methods}

The time series represents a chronological sequence of data that are spatially and materially comparable [16]. The financial time series are concerned with the theory and practice of financial market over time [17]. The time series can be modelled using different approaches. The commonly used for modelling the time series is one-dimensional model of real value [18]. The model has the shape of an elementary function of time:

$Y_{t}=f(t), t=1,2, \ldots, z$

where $z$ is the length of the series and $Y_{t}$ denotes the value of the series recorded in time unit $t$ [19].

The model can be created using two basic ways. The first way is to use the Box-Jenkins methodology. This methodology considers the basic element of the construction of the model time series random component, which may be taken as correlated random variables. Another option is to use the classical (formal) model of the time series decomposition into four components of time motion [20]: trend component $\left(T_{t}\right)$, seasonal component $\left(S_{t}\right)$, cyclical component $\left(C_{t}\right)$ and random component $\left(\varepsilon_{t}\right)$. Another possibility of expression describes Chan [21] - the time series is decomposed into a time trend part $\left(T_{t}\right)$, seasonal part $\left(S_{t}\right)$ and a microscopic part given by the noise $\left(N_{t}\right)$.

The time series decomposition into individual components can be done by adding the individual components of the time series where components are considered in their actual values. Or, as a result of the individual components of the time series, if it can be considered in the actual value of trend and other components are in relative terms against the trend.

When the seasonal component $S_{t}$ is present in equation, we can use the methods to determine this seasonality. The seasonal component can be described either by an additive model $\left(Y_{t}=T_{t}+S_{t}+N_{t}\right)$ or by a multiplicative model $\left(Y_{t}=T_{t} \times S_{t} \times N_{t}\right)[21]$.

For the simple additive model the procedure for calculating of seasonality effects is given as following steps [22]. We calculate $Y^{*}$ for each time point, it is the difference between the original value $\left(Y_{t}\right)$ and the trend $Y_{t}^{\prime}$, see Equation (2). We can determine the trend using the moving averages [23]:

$$
Y_{t}^{*}=Y_{t}-Y_{t}^{\prime}
$$

For each season, in turn, we can find the average of the $Y^{*}{ }_{t}$ values - the value $I_{j}^{*}$, represents the seasonal factor for each season $j(j=1, \ldots, n ; n$ represents number of seasons). We can subtract the average seasonal factor:

$$
I_{j}=I_{j}^{*}-\frac{I_{1}^{*}+\cdots+I_{n}^{*}}{n}
$$

The last step is to remove the seasonal component (see Equation (4)), to make seasonal adjustment. $Y^{\prime \prime}$, represents the data without seasonal effects, $j$ represents the season $(j=1, \ldots, n)$.

$Y_{t}^{\prime \prime}=Y_{t}-I$

Seasonal models are often multiplicative rather than additive [24]. For the simple multiplicative model the procedure for calculating is given as following steps [22]. We calculate $Y^{*}$, for each time point, it is the proportion between the original value $\left(Y_{t}\right)$ and the trend $Y^{\prime}$, see Equation (5). We determine the trend using the moving averages [23].

$Y_{t}^{*}=\frac{Y_{t}}{Y_{t}^{\prime}}$

For each season, in turn, we find the average of the $Y_{t}^{*}$ values - the value $I_{j}^{*}$ represents the seasonal factor for each season $j(j=1, \ldots, n ; n$ represents number of seasons). We can use the average seasonal index (see Equation (6)).

$$
I_{j}=\frac{I_{j}^{*}}{\sqrt[n]{I_{1}^{*} \cdot \ldots \cdot I_{n}^{*}}}
$$

The last step is to remove the seasonal component (see Equation (7)), to make seasonal adjustment. $Y^{\prime \prime}{ }_{t}$ represents the data without seasonal effects, $j$ represents the season.

$Y_{t}^{\prime \prime}=\frac{Y_{t}}{I_{j}}$

For a more detailed analysis and description of seasonal component can we use the following steps [25]: identification of the seasonal component, the seasonal component estimate (to quantify it), removing the seasonal component (to adjust the time series).

The first step is to get an idea about the character of the process, which is represented by the time series [26]. The simplest methods include visual analysis using time series graph. The second step is to use elementary statistical characteristics [27, 28].

The first difference characterizes the absolute change (increase or decrease) of the value of indicators point in time $t$ compared to the previous period $(t-1)$. Indicator $t$ takes values from 2 to $n$ ( $n$ is the number of observations). It can be calculated using the following equation:

$\Delta^{(1)} y_{t}=y_{t}-y_{t-1}$

The second difference (differential of acceleration), is based on the difference of the two adjacent first absolute differences in the time moments $(t-1)$. Indicator $t$ takes values from 3 to $n$ ( $n$ is the number of observations). It can be calculated using the following equation: 


$$
\Delta^{(2)} y_{t}=\Delta^{(1)} y_{t}-\Delta^{(1)} y_{t-1}
$$

The rate of growth (chain index number) indicates the percent increase of the time series at time $t$ contrary to the previous time $(t-1)$. Indicator $t$ takes values from 2 to $n$ ( $n$ is the number of observations). It can be calculated using the following equation:

$$
k_{t}=\frac{y_{t}}{y_{t-1}}
$$

It is necessary to identify whether these fluctuations are statistically significant. In some cases the existence of seasonality could be revealed intuitively. In the more complex cases the answer could be obtained by the statistical verification.

To verify the hypothesis of the existence of seasonality in the time series, the existence of seasonality test could be used. The test takes the form of the F - test with $(n-1)$ and $(n-1) .(m-1)$ degrees of freedom [29].

The null hypothesis $\mathrm{H}_{0}$ is tested. The hypothesis assumes that all indices in seasonal time series are zero. The form of hypothesis: $H_{0}: S_{j}=0$ for $j=1, \ldots, r$

Null hypothesis is against the alternative hypothesis $\mathrm{H}_{1} \cdot \mathrm{H}_{1}$ assumes that at least one index in the seasonal time series is nonzero. The form of hypothesis: $H_{1}$ : non $H_{0}$

The test statistics has following form:

$$
F=\frac{\frac{m \sum_{j=1}^{n}\left(\bar{y}_{j}-\bar{y}\right)^{2}}{r-1}}{\frac{S_{R}}{(n-1) \cdot(m-1)}}
$$

$S_{R}=\sum_{i=1}^{m} \sum_{j=1}^{n}\left(y_{i j}-\bar{y}\right)^{2}-n \sum_{i=1}^{m}\left(\bar{y}_{i .}-\bar{y}\right)^{2}-m \sum_{j=1}^{n}\left(\bar{y}_{j}-\bar{y}\right)^{2}(14)$

where:

$m$ the number of time intervals (years),

$n$ the number of incremental time periods (seasons),

$\bar{y}$ the average oftime interval,

$\bar{y}_{j}$ the average value in the $j$ - th season,

$\bar{y}_{i}$, the average value in the $i$ - th interval.

Result of the test will be compared to the critical F-value distribution. It the value of the F-test statistics is greater than the critical value, the null hypothesis is rejected. If there is a seasonal time series component, it is necessary to quantify the seasonal variations and describe the seasonal component. The most common technique is the construction of indexes and seasonal differences, or the classical regression approach to the seasonal component.

We can use an additive model [22]; there are two options. If there is a trend in the series and the size of the seasonal effect appears to increase with the mean, then it may be advisable to transform the data so as to make the seasonal effect constant (this concept of seasonality is called the constant seasonality, the concept of constant seasonality can be described either by the linear trend or stepped trend). Or the size of the seasonal effect is said to be multiplicative (this concept of seasonality is called the proportional seasonality) [30,31].

The model of the constant seasonality and the seasonal differences $\left(b_{j}\right)$ can be described using the following equations: [32]

$Y_{i j}=T_{i j}+S_{i j}+\varepsilon_{i j}$

$S_{i j}=b_{j}$

$\sum_{j=1}^{n} b_{j}=0$

$\bar{b}_{j}=\frac{1}{m} \sum_{i=1}^{m}\left(Y_{i j}-T_{i j}\right)$

where:

$m$ the number of time intervals (years),

$n$ the number of incremental time periods (seasons),

$i$ the time intervals (year), $i=1,2, \ldots, m$,

$j$ the time periods (season), $i=1,2, \ldots, r$,

$b_{j}$ the seasonal difference,

$\bar{b}_{j}$ the average seasonal difference.

The model of the proportional seasonality, the seasonal parameters $\left(c_{j}\right)$ and seasonal indexes $\left(1+c_{j}\right)$ can be described using the following equations:

$Y_{i j}=T_{i j}+S_{i j}+\varepsilon_{i j}$

$S_{i j}=c_{j} \times T_{i j}$

$Y_{i j}=\left(1+c_{j}\right) T_{i j}+\varepsilon_{i j}$

$\left(1+\hat{c}_{j}\right)=\frac{\sum_{i=1}^{m} y_{i j} \cdot T_{i j}}{\sum_{i=1}^{m} T_{i j}^{2}}$

where:

$m$ the number of time intervals (years),

$n$ the number of incremental time periods (seasons),

$i \quad$ the timeintervals (year), $i=1,2, \ldots, m$,

$j \quad$ the time periods (season), $i=1,2, \ldots, r$,

$\left(1+c_{j}\right)$ the seasonal index,

$\left(1+\hat{c}_{j}\right)$ the estimated seasonal index.

The choice of the model can be confirmed by analysis of the empirical data - the index of determination [33].

The last step is the seasonal adjustment of the time series. Methods of seasonal adjustment are usually based on different types of moving averages. Furthermore, the regression methods or special filters is used. We can use the Equation (4) for the additive model or Equation (7) for the multiplicative model and we can use special filters, as well. We can adjust the time series by a Henderson moving average filter. Filter values for quarterly data are (- 0.073 , $-0.294,0.558,0.294,-0.073)$. We use special filter for the first 
Table 1 Total written premiums (CZK)

\begin{tabular}{|c|c|c|c|c|}
\hline \multirow{2}{*}{ Year } & \multicolumn{4}{|c|}{ Quarter } \\
\hline & I. & II. & III. & IV. \\
\hline 2000 & 8238250051 & 1280894987 & 1939802791 & 1302995043 \\
\hline 2001 & 8551967975 & 2435886956 & 2429250249 & 2107394158 \\
\hline 2002 & 8785018870 & 2635259903 & 2940351869 & 3321244275 \\
\hline 2003 & 9017700717 & 3387194231 & 3768388913 & 3525820090 \\
\hline 2004 & 8585094323 & 4020838244 & 4204559935 & 4150365492 \\
\hline 2005 & 8165886283 & 4315786804 & 4649390901 & 4565761580 \\
\hline 2006 & 7533299839 & 4879077613 & 4835398027 & 4859864426 \\
\hline 2007 & 7316111159 & 5284682766 & 5131876172 & 5217300715 \\
\hline 2008 & 7377390462 & 5528561938 & 5369001117 & 5433909496 \\
\hline 2009 & 7304281899 & 5588876693 & 5433887480 & 5447997444 \\
\hline 2010 & 6574423103 & 5510400176 & 5089435430 & 5169296336 \\
\hline 2011 & 5977322299 & 3468702668 & 4686205694 & 3261509297 \\
\hline 2012 & 5433731712 & 4865010097 & 4568434435 & 4604652313 \\
\hline 2013 & 5315651506 & 4867612572 & 4466550550 & 3125507531 \\
\hline 2014 & 5440668934 & 5065328774 & 4647015809 & 4887662401 \\
\hline 2015 & 5423764786 & 5240604470 & 4868146979 & 5034794468 \\
\hline 2016 & 5518494871 & 5420106857 & 4933182417 & 5099435130 \\
\hline
\end{tabular}

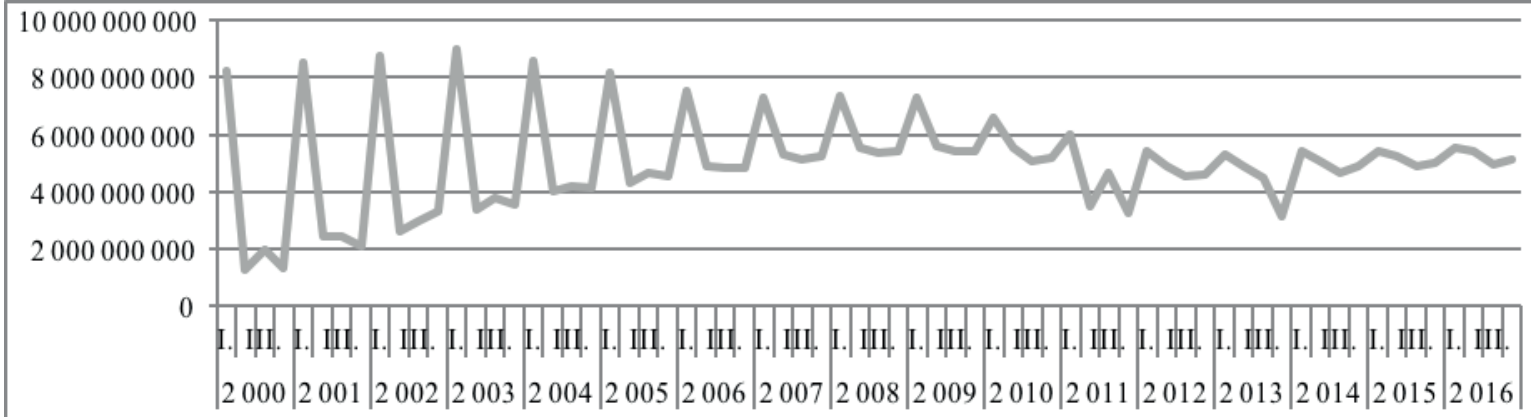

Figure 1 Total written premiums $(C Z K)$

adjusted value $\left(Y_{1}^{\prime}\right)$, the second adjusted value $\left(Y_{2}^{\prime}\right)$, the last adjusted value $\left(Y_{z}^{\prime}\right)$ and the penultimate adjusted value $\left(Y_{z-1}^{\prime}\right)$ : [34]

$Y_{1}^{\prime}=0.670 Y_{1}+0.403 Y_{2}-0.073 Y_{3}$

$Y_{z}^{\prime}=0.670 Y_{n}+0.403 Y_{n-1}-0.073 Y_{n-2}$

$Y_{2}^{\prime}=0.257 Y_{1}+0.522 Y_{2}+0.294 Y_{3}-0.073 Y_{4}$

$Y_{z-1}^{\prime}=0.257 Y_{n}+0.522 Y_{n-1}+0.294 Y_{n-2}-0.073 Y_{n-3}$

\section{Data}

The motor third party insurance was required by law until 2000 [35]. An Act No. 168/1999 Coll. - Motor Third Party Liability Insurance act on liability insurance for damage caused by operation of vehicle and on amendments to certain related acts (the Motor Third Party Liability Insurance Act) coming into force in 2000 [36]. The motor third party insurance is mandatory according to the new law. The development of this type of insurance in the period 2000 to 2016 shows the following Table 1. The data in the table are given in Czech crowns and show the trend of total written premiums.

\section{Results}

Using visual analysis of time series (Figure 1) it can be said that the time series has each year a polynomial character with the effects of seasonality.

By using the elementary statistical analysis of the characteristics, it can be said that the time series recorded increase 
Table 2 Seasonal factors and seasonal indexes

\begin{tabular}{ccc}
\hline Season & Average seasonal factor - simple additive model $[\mathrm{CZK}]$ & Average seasonal factor - simple multiplicative model [-] \\
\hline I. & 2004576118 & 1.4732 \\
II. & -536399222 & 0.9130 \\
III. & -634430530 & 0.8878 \\
IV. & -833746366 & 0.8374 \\
\hline
\end{tabular}

Table 3 Seasonal differences and seasonal indexes

\begin{tabular}{cccc}
\hline \multicolumn{3}{c}{ Constant seasonality } & \\
Season & Linear trend - seasonal differences [CZK] & Stepped trend - seasonal differences [CZK] & $\begin{array}{c}\text { Proportional seasonality } \\
\text { - seasonal index [-] }\end{array}$ \\
\hline I. & 2120294316 & 2100087671 & 1.3747 \\
II. & -644014018 & -650749566 & 0.8868 \\
III. & -647717290 & -640981742 & 0.8835 \\
IV. & -828563008 & -808356364 & 0.8563 \\
\hline
\end{tabular}

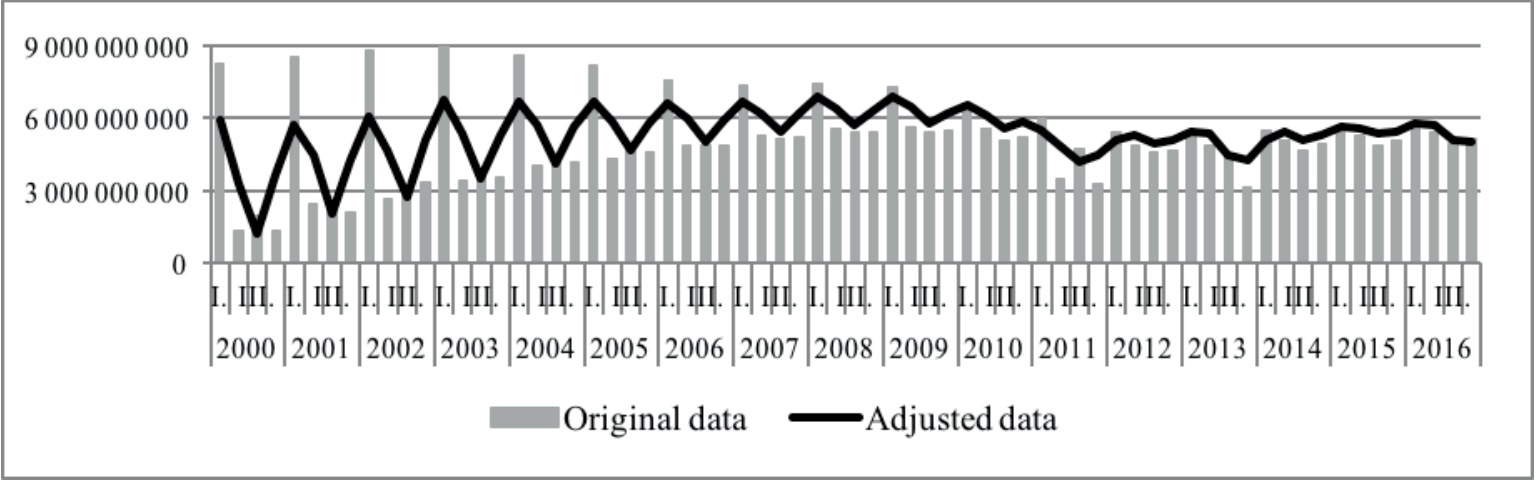

Figure 2 Adjusted data (CZK)

in the first quarter of each year, and conversely a decline in the second quarter of each year. This fact points to the same conclusion to be drawn from the analysis of the graph, the time series is affected by seasonal influences. The seasonal component $S_{t}$ is described using the simple additive model (average seasonal factors) and the simple multiplicative model (average seasonal factor), see Table 2.

Seasonal influences in the time series with a periodicity of less than one year can be found almost always. We used the F-test for statistically significant confirmation. We chose significance level $\alpha=0.05$, degrees of freedom are 3 and 48 . The critical value is equal to 2.7985 . The value of the test statistics $F$ was higher than the critical value (26.637), the null hypothesis is rejected since there is a significant seasonality.

We used the concept of constant seasonality (we determined seasonal differences for linear trend and for the stepped trend) and the concept of proportional seasonality (we determined seasonal indexes), see Table 3 .

The choice of appropriate model among other options was confirmed by analysis of empirical data-we used index of determination. The value of the index of determination was: 0.52 (the concept of constant seasonality-linear trend), 0.69 (the concept of constant seasonality-stepped trend), 0.92 (the concept of proportional seasonality). The coefficient of determination generally takes values from the interval $\langle 0,1\rangle$. The more are functions apposite, the more is the coefficient of determination closer to one. The selected concept (the concept of proportional seasonality) explains $92 \%$ of the values of variables.

The last step was the seasonal adjustment of the time series. We chose adjustment of the time series by a Henderson moving average filter. This method is commonly used in practice. The method allows adjustment of limit values and time series. The following graph shows the results-comparison of original and adjusted values (see Figure 2).

Seasonal adjustment is done because there is a need of continuous comparison of consecutive data. After elimination of the seasonal component, in the model remain the trend component, the cyclical component and a random component (if any). 


\section{Discussion}

The problem of demand variability and seasonality is solved by many experts not only on the theoretical level, because demand seasonality affects some businesses and some sectors daily. There are currently many professional studies that focus on the problem of demand seasonality, especially in services such as accounting, tourism, advertising, construction, restaurants, communications, construction materials, education, public utilities, employment agencies, logistics services and financial services [8 - 11]. However, there is currently no relevant study or sources to analyse demand seasonality in the insurance sector or of the specific insurance product. Otherwise some authors emphasize the need to analyse and monitor the demand for insurance products and its variability over time related not only to the working capital [5 - 7]. Seasonality of demand is a very important parameter for marketing planning in general, especially for planning of marketing campaigns and activities, and for marketing and business strategy [8 - 11]. The seasonality of demand for motor third party liability insurance has been confirmed for the Czech Republic in years 2000 - 2016, based on the research results (Section 4). Insurance companies should reflect the results of research when developing the marketing strategy, preparing marketing campaigns or activities, because it is necessary to implement these activities in accordance with demand for insurance products.

\section{Conclusion}

The current turbulent market environment is very competitive and insurance companies need information about demand for insurance products, as much as possible. This information can be used to increase the competitiveness of insurance companies and for more efficient planning of marketing activities, especially in the situation where the demand is growing (due to seasonality). If there is a seasonal demand in any given sector, companies need the most accurate information about the seasonality of the demand. The motor third party liability insurance in the Czech Republic in 2000 - 2016 is seasonal, based on the research results, which implies necessity to take this into account when planning any business activities, especially for marketing activities. The combination of an increase of demand (due to seasonality) and application of appropriate marketing strategy can get a better position on the market for insurance company.

\section{Acknowledgement}

This article is published within the realization of the project no. SGS_2017_009 „Traffic Engineering, Technology and Management”.

\section{References}

[1] MESRSMID, J.: Insurance Marketing (in Czech). Kamil Marik - Professional Publishing, Praha, 2016.

[2] SHIU, Y. - M., YU, T. - W.: Internal Marketing, Organisational Culture, Job Satisfaction, and Organisational Performance in Non - Life Insurance. The Service Industries Journal, 30(6), 793-809, 2010.

[3] REZAC, F., et al.: Marketing Management of Commercial Insurance Company (in Czech). Masaryk University, Brno, 2009.

[4] COle, C., MARONEY, P., MCCUllough, K., POWEll, L.: Automobile Insurance Vehicle Repair Practises: Politics, Economics, and Consumer Interests. Risk Management and Insurance Review, 18(1), 101-128, 2015.

[5] BAHLOUL, W., BOURI, A.: The Efficiency of the European Non - Life Insurance: CEO Power, Macroeconomic, and Market Characteristics Impact. International Journal of Financial Studies, 4(1), 1-13, 2016.

[6] CHAMBERS, J. M.: An Econometric Model of the Aggregate Motor Insurance Market in the United Kingdom. The Journal of Risk and Insurance, 59(3), 409-425, 1992.

[7] PADMALATHA, S.: Management of Banking and Financial Services. Pearson Education India, Noida, 2011.

[8] RUST, T., HUANG, M. - H.: Handbook of Service Marketing Research.Edward Elgar Publishing, Cheltenham, 2014.

[9] ROSSELLO, J., SANSO, A.: Yearly, Monthly and Weekly Seasonality of Tourism Demand: A Decomposition Analysis. Tourism Management, 60, 379-389, 2017

[10] EHRENTHAL, J. C. F., HONHON, D., WOENSEL, T. V.: Demand Seasonality in Retail Inventory Management. European Journal of Operational Research, 238(2), 527-539, 2014

[11] SCALERA, D., ZAZZARO, A.: The Unpleasant Effects of Price Deregulation in the European Third-Party Motor Insurance Market: A Theoretical Framework. The B.E. Journal of Economic Analysis \& Policy, 7(1), 1-28, 2007.

[12] CEJKOVA, V.: Insurance Market (in Czech). Grada Publishing, Praha, 2002.

[13] DOMINIQUE - FERREIRA, S.: How Important Is the Strategic Order of Product Attribute Presentation in the Non-Life Insurance Market? Journal of Retailing and Consumer Services, 34, 138-144, 2017. 
[14] TOMESKI, B.: Development of Motor Third Party Liability Insurance Market in Terms of Changing Regulation. Procedia - Social and Behavioural Sciences, 44, 200-209, 2012.

[15] TRANSPORT YEARBOOK 2015: Number of the Road Vehicles Registered in the Czech Republic. Transport Yearbook 2015[online]. Available: http://www.sydos.cz/cs/rocenka-2015/yearbook/htm_uk/uk15_420100.html (accessed 2017-06-24).

[16] PILLAI, R. S. N.: Statistics (Theory \& Practice). S. Chand Publishing, New Delhi, 2008.

[17] ARLT, J.: Financial Time Series in Czech). Grada Publishing, Praha, 2003.

[18] MILHOJ, A.: Multiple Time Series Modelling Using the SAS VARMAX Procedure. North SAS Institute Inc., Carolina, 2016.

[19] DIGGLE, P. J., CHETWYND, A. G.: Statistics and Scientific Method. Oxford University Press, Oxford, 2011.

[20] MILLS, T.: Modelling Trends and Cycles in Economic Time Series. Palgrave Macmillan UK, Hampshire, 2003.

[21] CHAN, N. H.: Time Series: Applications to Finance. John Wiley \& Sons, New York, 2004.

[22] FRANCIS, A.: Business Mathematics and Statistics. Cengage Learning EMEA, London, 2004.

[23] JAIN, D. R., JHUNJHUNWALA, B.: Business Statistics for B.Com (Hons). Tata McGraw - Hill Education, New Delhi, 2006.

[24] SAS INSTITUTE INC.: Forecasting Examples for Business and Economics Using the SAS System. SAS Institute Inc., North Carolina, 1996.

[25] KOCENDA, E., CERNY,A.: Elements of Time Series Econometrics: An Applied Approach. Karolinum, Praha, 2007.

[26] LUTKEPOHL, H., KRATZIG, M.: Applied Time Series Econometrics. Cambridge University Press, Cambridge, 2004.

[27] BUDIKOVA, M., KRALOVA, M., MARES, B.: Guideof Basic Statistical Methods (in Czech). Grada Publishing, Praha, 2010.

[28] MENARD, S. W.: Handbook of Longitudinal Research: Design, Measurement, and Analysis. Elsevier / Academic Press, San Diego, 2008.

[29] SHISKIN, J.: The X - 11 Variant of the Census Method II Seasonal Adjustment Program. U. S. Department of Commerce, Bureau of the Census, Washington D. C., 1967.

[30] CHATFIELD, CH.: The Analysis of Time Series: An Introduction, Sixth Edition. CRC Press, Boca Raton, 2016.

[31] SYNEK, M., KOPKANE, H., KUBALKOVA, M.: Managerial Calculations and Economic Analysis (in Czech). C. H. Beck, Praha, 2009.

[32] HINDLS R., KANOKOVA J., NOVAK I.: Methods of Statistical Analysis for Economists (in Czech). Management Press, Praha, 1997.

[33] WATSON, P. K., TEELUCKSINGH, S. S.: A Practical Introduction to Econometric Methods: Classical and Modern. University of the West Indies Press, Kingston, 2002.

[34] ZAPLETAL, J.: Introduction to Economic Time Series Analysis (in Czech). Novotny, Brno, 2000.

[35] CZECH REPUBLIC: Decree of the Ministry of Finance of the Czech Republic no. 492/1991 Coll., which stipulates the extent and conditions of statutory in surance for motor vehicle third party liability (in Czech). Collection of Law, 94, 2335-2341, 1991.

[36] CZECH REPUBLIC: Act No. 168/1999 Coll., Motor Third Party Liability Insurance act on liability insurance for damage caused by operation of vehicle and on amendments to certain related acts (the Motor Third - Party Liability Insurance Act) (in Czech). Collection of Law, 57, 3158-3168, 1999. 